\title{
A Note on Sex, Geographic Mobility, and Career Advancement
}

By: William T. Markham, Patrick O. Macken, Charles M. Bonjean, Judy Corder

This is a pre-copyedited, author-produced PDF of an article accepted for publication in Social Forces following peer review. The version of record

William T. Markham, Patrick O. Macken, Charles M. Bonjean, and Judy Corder, "A Note on Sex, Geographic Mobility, and Career Advancement," Social Forces, 61(4) (June, 1983), 11381146.

is available online at: http://dx.doi.org/10.1093/sf/61.4.1138

***(C) Oxford University Press. Reprinted with permission. No further reproduction is authorized without written permission from Oxford University Press. This version of the document is not the version of record. Figures and/or pictures may be missing from this format of the document. ***

Abstract:

The article presents information on sex, geographic mobility and career development. Over the past four decades, major changes in the extent and nature of female labor force participation have led to increased concern about the under-representation and lower pay of women in professional and managerial positions. Social scientists have offered a number of explanations for these disparities. One such explanation asserts that, with increasing career aspirations among women and greater prevalence of dual career marriages, sex differences in geographic mobility for occupational advancement are one barrier to women's career advancement. Both human capital theory and the crowding hypothesis suggest that lesser geographic mobility among women contributes to sex stratification in the labor force, and there is evidence that geographic mobility is related to income and occupational status. In addition, willingness to move may be valued by managers as a sign of organizational commitment.

Keywords: Labor force | Geographic mobility | Career development | Occupational development | Sex differences

\section{Article:}

Over the past four decades, major changes in the extent and nature of female labor force participation have led to increased concern about the underrepresentation and lower pay of women in professional and managerial positions. Social scientists have offered a number of explanations for these disparities. One such explanation asserts that, with increasing career aspirations among women and greater prevalence of dual career marriages, sex differences in geographic mobility for occupational advancement are one barrier to women's career advancement. 
Evidence we assembled from a case study of a federal agency and its employees indicates that migration is an important factor in career advancement in the agency and that women employees move less often and are less willing to do so. We also investigated the extent to which sex differences in willingness to transfer are reduced when factors related to both sex and willingness to move are controlled.

\section{Consequences and Causes of Sex Differences in Geographic Mobility}

Both human capital theory and the crowding hypothesis suggest that lesser geographic mobility among women contributes to sex stratification in the labor force, and there is evidence that geographic mobility is related to income and occupational status. In addition, willingness to move may be valued by managers as a sign of organizational commitment. Such mobility should be especially advantageous in large organizations, such as our agency, which have geographically dispersed offices with similar occupational structures and promotion systems allowing competition for jobs in other offices.

Sociologists and economists have uncovered a number of differences between men and women in the labor force and in large white collar organizations; most suggest that women will be less mobile and less willing to move. (1) More discontinuous labor force participation among women may reduce geographic mobility because women average fewer remaining years to recover the costs of migration. (2) Lower promotion opportunities among female employees may also lead to lower expectations of future benefits from a transfer. (3) Higher occupational status, especially among salaried employees, is associated with migration and willingness to move, but women in white collar organizations typically hold lower status positions. (4) Marital status is expected to have complex effects on geographic mobility. Human capital theory and exchange theory suggest that married persons will be less likely to move and that the partner with the lower wages will be especially unlikely to move for his or her own career advancement. Since employed women are less likely to be married than employed men, controlling marital status should actually increase the sex differences in mobility. However, a strong interaction effect should also appear. Married women with considerably lower incomes than their husbands should be especially unlikely to move. Hence the net effect should be less willingness to move among women. (5) Socialization and personality factors such as social self-esteem, high career aspirations, and non-traditional sex role attitudes may be positively linked to willingness to transfer. There is some evidence that women are less self-confident in social relations and have lower career aspirations. Women with less traditional sex role attitudes would also be expected to be less willing to move than women with traditional attitudes. (6) Women in white collar organizations tend to be less educated than men. Education is positively associated with migration and willingness to move, probably because of greater knowledge of job opportunities elsewhere, participation in more specialized labor pools, and lower psychic costs for moving. (7) Because of their lower occupational levels and lower percentage married, women in white collar organizations are probably less likely to own their own homes. Since home ownership generates additional monetary and psychic costs for moving and has been found to be negatively associated 
with migration, controlling it should actually increase the association between sex and willingness to move. (8) Length of community residence is negatively associated with willingness to move, and women in our sample averaged somewhat longer residence in their communities than men.

On balance, this discussion suggests that men employees will be more likely than women to transfer and more willing to do so. Although the tendency of wives to move to follow their husbands' careers makes simple demographic comparisons of male and female migration misleading, scattered demographic data do support our prediction, and there is considerable evidence that women hold less favorable attitudes toward mobility. However, it is possible that differences in willingness to move might be reduced when variables such as those listed above, are controlled.

\section{Data and Measures}

Data are from a study of six offices of a federal agency, with an entirely white collar work force, and occupations ranging from low level clerical to high level professional and managerial. This research relies on information from official personnel records for all employees, interviews with 32 of the 33 managers, and questionnaire responses from a systematic stratified sample of 897 employees and supervisors.

Actual geographic mobility for all employees was coded from personnel records showing each employee's status at the time of the study and 18 months earlier. Management opinions about mobility were derived from the interviews. The remaining variables were derived from the questionnaire. Willingness to be geographically mobile was measured with two items (alpha = .80). Career continuity was tapped with a questionnaire item about whether the respondent was the primary provider for his or her family. Promotion opportunity was measured by a 4-item index (alpha $=.72$ ) and occupational level by a slightly modified version of government service (cs) level. Social self-esteem was measured by an abbreviated version of Form B of the Texas Social Behavior Index (alpha = .92), and liberalism of attitudes toward women at work was measured by a Likert scale (alpha $=.91)$ constructed for this purpose. A 2-item index (alpha = .73) was used to tap promotion interest. The remaining variables were measured with single items. Primary reason for working (primary provider, secondary provider, or interest) and marital status (married, single, divorced) were coded as dummy variables. To further investigate the effect of marital status, we also asked respondents whether moving for promotion would lead to conflict with other family members.

\section{Results}

\section{ACTUAL MOBILITY}

Table 1 presents information about the extent of sex segregation and stratification in the offices and the prevalence of promotion and geographic mobility. The table shows the percentages of 
employees now in each of six occupational categories who, 18 months before, were (a) in the same office, category, and GS level, (b) in the same office and category but a lower GS level, (c) in the same office but a different category, (d) not working for the agency, and (e) employed by the agency in a different office. The last group comprise those who had been geographically mobile, in almost every case for promotion. The column marginals show that occupational level is strongly related to sex. The body of the table shows that there was substantial upward mobility within categories, but the limited mobility between them involved mainly adjacent categories. Newly hired employees entered mainly at either the clerical (almost entirely women) or the semiprofessional and professional levels (mainly men).

Table 1. STATUS OF EMPLOYEES IN MAJOR JOB CATEGORIES CURRENT AND 18 MONTHS EARLIER (IN PERCENT)

\begin{tabular}{|c|c|c|c|c|c|c|c|c|c|c|c|c|}
\hline & \multicolumn{12}{|c|}{ Current Job Category } \\
\hline & \multicolumn{2}{|c|}{ Clerical } & \multicolumn{2}{|c|}{ Technical } & \multicolumn{2}{|c|}{$\begin{array}{l}\text { Semi- } \\
\text { Professional }\end{array}$} & \multicolumn{2}{|c|}{ Professional } & \multicolumn{2}{|c|}{ Supervisor } & \multicolumn{2}{|c|}{ Manager } \\
\hline $\begin{array}{l}\text { Status } 18 \text { Months } \\
\text { Earlier }\end{array}$ & $\mathrm{M}$ & $\mathrm{F}$ & $\mathrm{M}$ & $\mathrm{F}$ & $\mathrm{M}$ & $\mathrm{F}$ & $\mathrm{M}$ & $\mathrm{F}$ & $\mathrm{M}$ & $\mathrm{F}$ & $\mathrm{M}$ & $\mathrm{F}$ \\
\hline Same & 59 & 41 & 28 & 32 & 47 & 31 & 40 & 22 & 56 & 28 & 52 & 100 \\
\hline $\begin{array}{l}\text { Promoted within } \\
\text { category }\end{array}$ & 7 & 17 & 17 & 18 & 20 & 15 & 28 & 16 & 5 & 20 & 3 & -- \\
\hline \multicolumn{13}{|c|}{ Promoted to category from: } \\
\hline Clerical & & & 5 & 27 & -- & 2 & -- & -- & 1 & 12 & -- & -- \\
\hline Technical & -- & -- & & & 0 & 9 & 0 & -- & 3 & 8 & -- & -- \\
\hline Semi-professional & -- & -- & 3 & -- & & & 3 & 9 & 7 & 16 & 3 & -- \\
\hline Professional & -- & -- & 1 & -- & 1 & 1 & & & 12 & -- & -- & -- \\
\hline Supervisor & -- & 1 & -- & 1 & 2 & 2 & 1 & 3 & & & 6 & $\begin{array}{l}- \\
11\end{array}$ \\
\hline Manager & -- & -- & -- & -- & -- & -- & 0 & -- & 3 & -- & & \\
\hline Hired from outside & 30 & 38 & 26 & 13 & 22 & 33 & 24 & 42 & 1 & 8 & -- & -- \\
\hline $\begin{array}{l}\text { Transfer between } \\
\text { offices }\end{array}$ & 5 & 3 & 21 & 9 & 9 & 6 & 4 & 8 & 12 & 8 & 35 & -- \\
\hline Total N & (44) & (396) & (78) & $(182)$ & $(384)$ & (124) & (773) & (64) & (121) & (25) & (31) & (2) \\
\hline
\end{tabular}

Note: Table excludes 44 employees who transferred into the agency from a division of the agency that was abolished during the period covered. Zeroes indicate less than .5 percent.

The data on interoffice mobility suggest that the agency requires very high mobility from managers; exactly one-third had moved during the previous 18 months! There is also substantial mobility among supervisors. Rates of transfer among professional and semi-professional personnel are much lower, probably because these occupations have long career ladders of more or less automatic promotions without a change of location. Transfer rates are much higher in the technical occupations, which are characterized by short promotion ladders, few automatic promotions, and fewer opportunities in each office. The lowest rates of transfer occur among clerical personnel. Men are more likely to be geographically mobile in every category except the professional occupations, though the difference is large only for the technical occupations and no sex comparison is possible among the managers, since only two were women. 


\section{MANAGEMENT INTERVIEWS}

Interviews with managers supported the notion that willingness to move is a significant factor in advancement, especially into management. In response to an open-ended question about why there were few women managers, 7 of the 32 interviewed mentioned limited mobility. The 18 managers at the top two levels were also asked directly whether geographic mobility was a factor in promotion and whether this was desirable. All responded that it was advantageous, and the majority considered this situation desirable. Most pointed out that willingness to transfer increases the number of opportunities open to an employee, and about a third suggested that it was good for the organization. A few stated that geographically mobile employees were more likely to be management material. The interview results thus support our interpretation of the data in Table 1, and they suggest that some managers see mobility as valuable in itself.

\section{WILLINGNESS TO BE GEOGRAPHICALLY MOBILE}

Verbal reports about willingness to move may not be perfect measures of later behavior, but they are probably related to it. Moreover, since not all potential movers will have that opportunity in any given period, willingness to move may actually be a better indicator of long-term mobility, and it will be less skewed. And if managers view employees who are willing to move as especially promotable, such attitudes may provide an advantage even if no mobility occurs. The perception that women are less willing to move may also lead to statistical discrimination against all women.

As hypothesized, the questionnaire data showed females less willing to move ( $\mathrm{r}=-25 ; \mathrm{p}<.00$ ), with a mean willingness to move score (1.85) about one unit lower than the men (2.91). Although the amount of variance explained by sex is not large, the response distributions by sex are noticeably different. Forty-one percent of women and 18 percent of men chose the responses indicating no willingness to move for both items in the measure.

\section{REASONS FOR SEX DIFFERENCES IN WILLINGNESS TO MOVE}

The theoretical literature is not sufficiently developed to suggest a comprehensive causal model of causes of geographic mobility, and our cross sectional data are not adequate to estimate such a model. However, we can reasonably examine a series of three variable models suggesting variables which intervene between sex and mobility or interact with sex to influence mobility. Willingness to move is used as the dependent variable here, since actual mobility is highly skewed, was measured for a period preceding administration of the questionnaire, and does not reflect attitudes of those who did not move.

Table 2 presents regression analysis results for these models. It shows the simple correlation of each intervening variable with sex (column I) and willingness to move (column II), the increment to explained variance in willingness to move when sex is added to the regression after each control variable (column III), and the partial relationships of sex and the control variable to 
willingness to move when both are in the equation (column IV). Since variables differed in the amount of missing data, pairwise deletion of missing cases was used and the zero order correlation of sex to willingness to move is shown in column II for each model.

Table 2. REGRESSIONS OF WILLINGNESS TO MOVE ON EACH CONTROL VARIABLE, SEX, AND EACH CONTROL VARIABLE PAIRED WITH SEX

\begin{tabular}{|c|c|c|c|c|c|c|c|c|c|c|c|c|c|c|c|c|}
\hline & \multicolumn{4}{|c|}{$\mathrm{I}$} & \multicolumn{5}{|c|}{ II } & \multicolumn{4}{|c|}{ III } & \multicolumn{3}{|c|}{ IV } \\
\hline & \multicolumn{4}{|c|}{$\begin{array}{c}\text { Relationship of } \\
\text { Control Variable to } \\
\text { Sex }\end{array}$} & \multicolumn{5}{|c|}{$\begin{array}{l}\text { Zero-Order Relationships of } \\
\text { Control Variable \& Sex to } \\
\text { Willingness to Move }\end{array}$} & \multicolumn{4}{|c|}{$\begin{array}{l}\text { Effect of Adding Sex } \\
\text { to Regression after } \\
\text { Control Variable }\end{array}$} & \multicolumn{3}{|c|}{$\begin{array}{c}\text { Partial } \\
\text { Relationships of } \\
\text { Control Variable } \\
\text { \& Sex to } \\
\text { Willingness to } \\
\text { Move }\end{array}$} \\
\hline & & & & & & & & & & \multicolumn{2}{|c|}{ Total } & \multicolumn{2}{|c|}{ Change } & & & \\
\hline & $\mathrm{N}$ & $\mathrm{r}$ & $\mathrm{r}^{2}$ & Sig. & $\mathrm{r}$ & $\mathrm{r}^{2}$ & B & Beta & Sig. & $\mathrm{R}^{2}$ & Sig & $\mathrm{R}^{2}$ & Sig. & B & Beta & Sig. \\
\hline $\begin{array}{l}\text { Reason for } \\
\text { working* }\end{array}$ & 845 & .46 & .21 & .00 & .32 & .10 & & & .00 & & & & & & & \\
\hline Added income & & .50 & .25 & .00 & $\begin{array}{c}- \\
.30\end{array}$ & .09 & $\begin{array}{c}- \\
1.78\end{array}$ & -.31 & .00 & & & & & $\begin{array}{c}- \\
1.51\end{array}$ & -.27 & .00 \\
\hline Interest & & .20 & .04 & .00 & $\begin{array}{c}- \\
.05\end{array}$ & .00 & -.71 & -.11 & .01 & & & & & -.53 & -.09 & .02 \\
\hline Sex & & & & & $\begin{array}{l}- \\
.24\end{array}$ & .06 & $\begin{array}{c}- \\
1.03\end{array}$ & -.24 & .00 & .33 & .00 & .01 & .02 & -.38 & -.09 & .02 \\
\hline $\begin{array}{l}\text { Perceived } \\
\text { promotion } \\
\text { opportunity }\end{array}$ & 693 & $\begin{array}{l}- \\
.12\end{array}$ & .01 & .00 & .11 & .01 & .07 & .11 & .00 & & & & & 0.4 & 0.7 & 0.6 \\
\hline Sex & & & & & $\begin{array}{c}- \\
.30\end{array}$ & .09 & $\begin{array}{c}- \\
1.25\end{array}$ & -.30 & .00 & .10 & .00 & 09 & .00 & $\begin{array}{c}- \\
1.21\end{array}$ & -.29 & .00 \\
\hline Marital Status* & 865 & .26 & .07 & .00 & .17 & .03 & & & .00 & & & & & 1.23 & .18 & .00 \\
\hline Single & & .10 & .01 & .00 & .13 & .02 & .97 & .14 & .00 & & & & & 1.23 & .18 & .00 \\
\hline Divorced/Separated & & .23 & .04 & .00 & .09 & .01 & .83 & .11 & .00 & & & & & 1.41 & .18 & .00 \\
\hline Sex & & & & & .25 & .06 & $\begin{array}{c}- \\
1.08\end{array}$ & -.25 & .00 & .12 & .00 & .09 & .00 & $\begin{array}{c}- \\
1.34\end{array}$ & $\begin{array}{c}- \\
0.31\end{array}$ & .00 \\
\hline $\begin{array}{c}\text { Texas social } \\
\text { behavior inventory }\end{array}$ & 863 & .00 & .00 & .48 & .14 & .02 & .04 & .13 & .00 & & & & & .04 & .14 & .00 \\
\hline Sex & & & & & $\begin{array}{c}- \\
.25\end{array}$ & .06 & $\begin{array}{c}- \\
1.08\end{array}$ & -.25 & .00 & .08 & .00 & .06 & .00 & $\begin{array}{c}- \\
1.06\end{array}$ & -.25 & .00 \\
\hline $\begin{array}{l}\text { Interest in } \\
\text { promotion }\end{array}$ & 889 & $\begin{array}{c}- \\
.01\end{array}$ & .00 & .35 & .25 & .06 & .38 & .25 & .00 & & & & & .37 & .25 & .00 \\
\hline Sex & & & & & $\begin{array}{c}- \\
.25\end{array}$ & .06 & $\begin{array}{c}- \\
1.05\end{array}$ & -.24 & .00 & .12 & .00 & .06 & .00 & $\begin{array}{c}- \\
1.03\end{array}$ & -.24 & .00 \\
\hline Education & 881 & $\begin{array}{l}- \\
.53\end{array}$ & .28 & .00 & .23 & .05 & .52 & .23 & .00 & & & & & .31 & .14 & .00 \\
\hline Sex & & & & & $\begin{array}{c}- \\
.25\end{array}$ & .06 & $\begin{array}{c}- \\
1.05\end{array}$ & -.25 & .00 & .08 & .00 & .02 & .00 & -.73 & -.17 & .00 \\
\hline Home ownership & 860 & $\begin{array}{c}- \\
.14\end{array}$ & .02 & .00 & $\begin{array}{c}- \\
.22\end{array}$ & .05 & $\begin{array}{c}- \\
1.06\end{array}$ & -.22 & .00 & & & & & $\begin{array}{c}- \\
1.25\end{array}$ & -.26 & .00 \\
\hline Sex & & & & & $\begin{array}{c}- \\
.25\end{array}$ & .06 & $\begin{array}{c}- \\
1.03\end{array}$ & -.24 & .00 & .12 & .00 & .07 & .00 & $\begin{array}{c}- \\
1.17\end{array}$ & -.28 & .00 \\
\hline
\end{tabular}




\begin{tabular}{|c|c|c|c|c|c|c|c|c|c|c|c|c|c|c|c|c|}
\hline $\begin{array}{l}\text { Years in the } \\
\text { community }\end{array}$ & 885 & - & .01 & .00 & - & .10 & -.05 & -.31 & .00 & & & & & -.05 & -.29 & .00 \\
\hline Sex & & & & & - & .06 & - & -.25 & .00 & .14 & .00 & .05 & .00 & -.93 & -.22 & .00 \\
\hline
\end{tabular}

*Dummy Variable Coding. Header line contains multiple correlations with sex (column I) and willingness to move (column II).

In general, relationships in the table are in the directions expected, although there are a few exceptions and some are weak. Only the most interesting results are highlighted below.

Controlling for the attitude and personality measures had no effect on the association between sex and willingness to move. Both social self-esteem and promotion interest were related to willingness to move, but neither was related to sex. The results for sex role attitudes are not shown in Table 2, since this variable should predict willingness to transfer only among women. Women with less traditional attitudes did express greater willingness to move $(r=.20 ; p=.00 ; n$ = 396), but mean willingness to move among women in the most liberal octile of sex role attitudes (2.32) was well below the mean for all men.

The multiple correlation between reason for working and willingness to move was moderately strong, and the relationships of the dummy variables to willingness to move were as predicted. However, the response distribution for this item among men was highly skewed; 94 percent of men, compared to 42 percent of women, claimed to be primary providers, and only one percent said they worked for added income. Hence, the results in columns III and IV must be interpreted very cautiously. Nevertheless the mean values of willingness to move broken down by sex and reason for working reveal an easily interpretable pattern. Among primary providers, willingness to move is only slightly higher among males (means of 2. 91 and 2.61). Only 3 men said they were secondary providers, but the 143 women choosing this response reported very low willingness to move (mean =1.05). The 28 men who work primarily for interest are almost as willing to move (mean= 2.82) as the primary providers, but women in this category are much less willing to transfer.

As predicted, controlling for marital status slightly increases the association between sex and willingness to move, since women employees are slightly less often married and married persons are less willing to move. Surprisingly, a test of the predicted interaction of sex and marital status (not shown in Table 2) did not reach significance, since marriage depresses willingness to move about equally among men and women (means of 2.78 and 1.42). Results from the question about family conflict shed some additional light on the effects of family obligations on attitudes toward moving. Women were more likely to report that moving could cause family conflict, and such conflict had a moderate, negative effect on willingness to move. Thus, controlling for family conflict reduced the association between sex and willingness to move. Both sex and marital status (multiple $\mathrm{R}=.23$ ) were related to family conflict in moving, but they leave substantial variance in it unexplained. The regression of willingness to move on both marital status and conflict over moving (results not shown) explained 20 percent of the variance in willingness to 
move, but adding sex increases the explained variance by another 5 percent. These results suggest that unmarried women employees are less subject to conflict and thus more willing to move than their married counterparts, but whatever their marital status, women are more likely than men to experience family conflict over moving and this, in tum, reduces their mobility. Finally, there are effects of sex that operate to reduce willingness to move independent of family conflict or marital status.

Exploratory multiple regression analyses using sex and several combinations of control variables were also conducted to supplement the analyses in Table 2. In these analyses, stepwise regression excluding sex was first used to select the best predictors of willingness to move. Sex was then entered to see whether it would explain additional variance. Among the variables applicable to both men and women, five items-years in the community, promotion interest, GS level, home ownership, and the dummy variable for divorced or separated-entered the equation using 95 percent confidence limits, explaining 22 percent of the variance in willingness to move. However, adding sex produced an increment of .02 in explained variance, suggesting that sex has effects that are not easily eliminated by controlling other variables. None of our multiple regression analyses-including those which entered reason for working-reduced the sex increment in explained variance below .01, and sex always remained statistically significant.

\section{Discussion and Conclusions}

Our results suggest, first, that the efficacy of moving is situational. Mobility was clearly almost an occupational requirement for managers, and it may have helped in gaining supervisory positions, but it was much less frequent in most other occupations. Where there are many employees in an office, frequent vacancies, and workable career ladders exist, mobility may provide only slight advantage. And if there are no workable career ladders, mobility cannot help much. Nevertheless, managers did believe mobility helped with advancement and many believed requiring mobility was good policy. Hence, persons who made it clear that they were not willing to move, ran the risk of being labelled unsuitable for high level positions. In this respect, mobility and attitudes toward it may be important indeed.

Sex differences in actual mobility and willingness to move appeared as expected. Though not strikingly large, they were big enough to be noticed by managers sensitive to the issue. However, several other factors were more closely related to willingness to move than sex, and these factors affected both sexes. Many men were quite unwilling to move, and there were women who were just as willing as most men to move.

The most crucial sex difference affecting willingness to move was evidently that males generally saw themselves as primary providers, while the majority of women did not. Unlike women in any other category, women who saw themselves as primary providers were just as willing to move as similarly situated men. Although this outcome probably does relate to greater expected career continuity, it may also reflect simple economic necessity. Most of the other variables 
identified as predictors of mobility in the literature performed as expected although the relationships were often weak. Considered separately, education, grade level, and lack of family conflict over moving had the most impact in reducing the amount of variation explained by sex, but none completely eliminated it. Multiple regression analysis also suggested that the relationship of sex and willingness to move is quite persistent.

More generally, this shows that the relationships between sex, geographic mobility, and occupational advancement are of interest both theoretically and practically. Additional research in organizations and with national samples should yield provocative insights for theorists and useful guidelines for practitioners. 